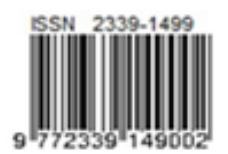

Jurnal Rekayasa Sistem Industri

Volume 9 No 3 - Oktober 2020

http://journal.unpar.ac.id/index.php/jrsi/index

ISSN 2339-1499 (online) - ISSN 0216-1036 (print)

Disampaikan : 10 Agustus 2020
Direview : 30 Agustus 2020

Diterima : 6 September 2020

\title{
Penerapan Metode Hybrid Genetic Algorithm (GA) dan Pattern Search (PS) untuk Penjadwalan Mata Kuliah Universitas
}

\author{
Fani Puspitasari ${ }^{1}$, Parwadi Moengin ${ }^{2}$ \\ 1,2) Fakultas Teknologi Industri, Jurusan Teknik Industri, Universitas Trisakti \\ Jl. Kyai Tapa No. 1, Jakarta 11440 \\ E-mail: fani.puspitasari@trisakti.ac.id, parwadi@trisakti.ac.id
}

\begin{abstract}
The problem of university course scheduling is a complicated job to do because of the many constraints that must be considered, such as the number of courses, the number of rooms available, the number of students, lecturer preferences, and time slots. The more courses that will be scheduled, the scheduling problem becomes more complex to solve. Therefore, it is necessary to set an automatic course schedule based on optimization method. The aim of this research is to gain an optimal solution in the form of schedule in order to decrease the number of clashed courses, optimize room utilization and consider the preferences of lecturer-course. In this research, a hybridization method of Genetic Algorithm (GA) and Pattern Search (PS) is investigated for solving university course scheduling problems. The main algorithm is GA to find the global optimum solution, while the PS algorithm is used to find the local optimum solution that is difficult to obtain by the GA method. The simulation results with 93 courses show that the Hybrid GA-PS method works better than does the GA method without hybrid, as evidenced by the better fitness value of the hybrid GA-PS method which is -3528.62 and $99.24 \%$ of the solutions achieved. While the GA method without hybrid is only able to reach a solution of around $65 \%$ and has an average fitness value of -3100.76 .
\end{abstract}

Keywords: course scheduling, optimization, hybrid genetic algorithm methods, pattern search method

\begin{abstract}
Abstrak
Masalah penjadwalan mata kuliah universitas adalah sebuah pekerjaan yang rumit untuk dikerjakan karena banyaknya kendala yang harus diperhatikan seperti jumlah mata kuliah, jumlah ruangan yang tersedia, jumlah mahasiswa, preferensi dosen dan slot waktu. Semakin banyak jumlah mata kuliah yang akan dijadwalkan maka semakin rumit penyelesaian masalah penjadwalan tersebut, oleh karena itu diperlukan adanya pengaturan jadwal mata kuliah otomatis berdasarkan metode optimasi. Tujuan dari penelitian ini adalah untuk mendapatkan solusi yang optimal dalam bentuk jadwal untuk mengurangi jumlah mata kuliah yang bentrok, mengoptimalkan pemanfaatan ruang dan mempertimbangkan preferensi dosen. Pada penelitian ini, metode yang digunakan untuk menyelesaikan masalah penjadwalan mata kuliah universitas adalah metode hybrid Genetic Algorithm (GA) dan Pattern Search (PS). Algoritma utama yang digunakan adalah GA untuk menemukan solusi optimum global sedangkan algoritma PS digunakan untuk mencari solusi optimum lokal yang sulit didapatkan oleh metode GA. Hasil simulasi dari 93 mata kuliah menunjukkan bahwa metode Hybrid GA-PS bekerja lebih baik dibandingkan metode GA tanpa hybrid, terbukti dari nilai rataan fitness value metode hybrid GA-PS yang lebih baik yaitu $-3528,62$ dan $99,24 \%$ solusi tercapai. Sedangkan metode GA tanpa hybrid hanya mampu mencapai solusi sekitar $65 \%$ dan memiliki nilai rataan fitness value $-3100,76$.
\end{abstract}

Kata kunci: penjadwalan mata kuliah, optimasi, metode hybrid genetic algorithm, metode pattern search

\author{
Pendahuluan \\ Penjadwalan mata kuliah merupakan \\ kegiatan yang rutin dilakukan oleh setiap
}

institusi pendidikan tingkat universitas di setiap pergantian semester. Tujuan dari penjadwalan mata kuliah adalah agar proses belajar mengajar dapat berjalan dengan baik, tidak 
hanya bagi mahasiswa yang mengambil mata kuliah tersebut, namun juga bagi dosen yang mengajar. Masalah penjadwalan tersebut menjadi pekerjaan yang rumit dikerjakan karena terdapat kendala yang harus diperhatikan. Kendala tersebut antara lain jumlah mahasiswa, jumlah ruangan yang tersedia, keterbatasan kapasitas ruangan dan keterbatasan jam mengajar dosen. Semakin banyak jumlah mata kuliah yang akan dijadwalkan maka semakin rumit penyelesaian masalah penjadwalan tersebut (Wati \& Rochman, 2013).

Selama ini, penjadwalan mata kuliah di banyaknya universitas masih dilakukan secara manual dan hal ini memungkinkan terjadinya human error sehingga menyebabkan adanya bentrok antar mata kuliah. Oleh karena itu, diperlukan adanya pengaturan jadwal mata kuliah otomatis dengan pendekatan metode optimasi sehingga dapat memudahkan penjadwalan yang bersifat kompleks dan dapat meng-cover banyaknya contsraint dalam melakukan penjadwalan.

Penelitian terkait penjadwalan mata kuliah dengan menggunakan metode Genetic Algorithm (GA) sudah banyak dilakukan, Priambodo, Nhita, \& Aditsania (2016) dan Anamisa, Djunaidy (2014) menerapkan metode hybrid Algoritma Genetika dan Algoritma Koloni Semut. Metode hybrid dua metode tersebut menghasilkan solusi yang lebih baik dibandingkan dengan tanpa hybrid. Wen-jing (2018) menerapkan metode improved adaptive genetic algorithm. Hasil penelitian menunjukkan bahwa metode improved adaptive genetic algorithm konvergen lebih cepat ke solusi dibandingkan metode GA biasa. Balcilar (2020) menerapkan metode GA dengan menambahkan preferensi dosen ke dalam formulasi penjadwalannya. Jat (2012) menerapkan metode Local search dan Guided Search pada metode GA untuk menghasilkan solusi dengan kualitas yang lebih baik.

Pada penelitian ini, penyelesaian penjadwalan mata kuliah dilakukan dengan metode Hybrid Genetic Algorithm (GA) dan Pattern Search (PS). Pemilihan Genetic Algorithm (GA) dalam penelitian ini adalah karena GA mampu menyelesaikan permasalahan yang memiliki tingkat kesulitan yang tinggi sehingga cocok untuk menyelesaikan masalah penjadwalan mata kuliah yang memiliki banyak variabel kendala
(Jat, 2012). Kelebihan lainnya dari GA adalah perhitungan matematis yang dilakukan sedikit dan operator-operator evolusi yang digunakan membuat algoritma ini sangat efektif pada pencarian global, dan memiliki fleksibilitas yang tinggi untuk di-hybrid-kan dengan metode pencarian lainnya agar lebih efektif (Gen \& Cheng, 1997).

Namun metode GA memiliki kelemahan yaitu tidak cukup efisien ketika menemukan nilai optimal pada proses mutasi iterasi-iterasi terakhir. Hal ini dikarenakan metode GA bekerja baik hanya di ruang pencarian solusi yang luas (global search), sedangkan tidak cukup baik untuk ruang solusi yang terbatas (local search) (Basak, Sanyal, Kumar, \& Goswami, 2013). Oleh karena itu, metode Pattern Search (PS) dihybrid kan ke dalam metode GA untuk mengatasi kelemahan metode GA tersebut. Metode PS dapat bekerja baik pada pencarian solusi dalam ruang solusi yang terbatas sehingga dapat menemukan nilai local optimum. Hal ini menjadi kelebihan metode Hybrid GA-PS jika dibandingkan dengan metode Hybrid GA lainnya karena dengan metode PS, masalah penjadwalan yang memiliki ruang solusi yg luas dapat ditemukan solusi local optimumnya.

Penelitian ini bertujuan menghasilkan solusi terbaik berupa sebuah jadwal yang mampu mengoptimalkan penggunaan berbagai sumber daya pembelajaran seperti ruang kelas, dosen, dan mahasiswa. Pada penelitian ini juga penjadwalan dilakukan dengan menambahkan preferensi dosen memilih jadwal mengajar pada time-slot, hari, dan kelas yang diinginkan.

\section{Metodologi}

\section{Penjadwalan Mata Kuliah}

Penjadwalan mata kuliah di universitas didefinisikan sebagai masalah penugasan multi-dimensi, dimana mahasiswa dan dosen di-assign ke dalam penyusunan daftar perkuliahan yang dimasukkan pada slot waktu dan ruang tertentu (Carter \& Laporte, 1996). Dalam penjadwalan mata kuliah, terdapat batasan atau kendala, yang terdiri dari kendala mutlak (hard constraint) dan kendala lunak (soft constraint).

Kendala mutlak (hard constraint) adalah kendala yang mutlak diperlukan, bila salah satu kendala tidak dipenuhi, maka perkuliahan tidak akan berjalan. Sedangkan kendala lunak (soft constraint) adalah kendala yang tidak mutlak 
perlu terpenuhi. Namun jika kendala mutlak dan kendala lunak dipenuhi, maka dapat dikatakan solusi penjadwalan telah optimal.

Solusi penjadwalan dapat dibagi ke dalam solusi layak, solusi tidak layak dan solusi optimal. Solusi layak adalah solusi yang memenuhi semua kendala mutlak (hard constraint) tetapi tidak harus semua memenuhi kendala lunak (soft constraint). Solusi tidak layak adalah solusi yang tidak berhasil memenuhi semua kendala, baik kendala mutlak maupun kendala lunak. Solusi optimal adalah solusi yang memenuhi semua persyaratan kendala dan tidak ada pelanggaran kendala mutlak dan lunak (Jat, 2012).

\section{Metode Genetic Algorithm (GA)}

Metode Genetic Algorith (GA) pertama kali diperkenalkan oleh John Holland pada tahun 1960 berdasarkan konsep teori Evolusi Darwin, lalu dikembangkan oleh David E Goldberg pada 1989. Metode GA terinspirasi dari proses seleksi genetika makhluk hidup yang diterapkan menjadi algoritma komputasi dan dapat digunakan untuk mencari solusi masalah optimasi. Konsep yang diadopsi ke dalam metode GA yaitu bahwa makhluk hidup dapat mempertahankan kelangsungan hidupnya dengan melalui proses reproduksi, mutasi dan crossover (Sivanandam \& Deepa, 2008).

GA memiliki beberapa kelebihan yaitu algoritma ini hanya melakukan sedikit perhitungan matematis yang berhubungan dengan masalah yang ingin diselesaikan. Kelebihan lain adalah metode GA dapat mencari solusi optimal secara global, artinya dapat mencari nilai optimal dari keseluruhan rentang input data (Erben \& Kepler, 1995). Kemudian operator-operator evolusi yang digunakan membuat algoritma ini sangat efektif pada pencarian global, dan memiliki fleksibilitas yang tinggi untuk di-hybrid-kan dengan metode pencarian lainnya agar lebih efektif. GA juga memiliki kekurangan yaitu adanya kemungkinan terjadinya masalah dalam melakukan identifikasi fungsi fitness, dan dalam mendefinisikan suatu permasalahan, terjadinya konvergensi yang prematur, banyaknya parameter yang digunakan seperti jumlah populasi (population size), parameter mutasi, parameter crossover, dan yang terakhir tidak dapat digunakan untuk permasalahan local optimal (Sivanandam \& Deepa, 2008).
Dalam metode Genetic Algorithm (GA), salah satu kemungkinan solusi optimal disebut sebagai individu. Kumpulan individu membentuk populasi yang merupakan sejumlah kemungkinan solusi. Tahap pertama dalam GA adalah representasi kromosom yaitu mengetahui tipe data seperti apa yang akan diteliti untuk selanjutnya diproses ke dalam skema pengkodean. Tipe data kromosom dapat berupa nilai biner, float, integer, karakter, maupun kombinatorial. Kumpulan kromosom yang dibangkitkan dengan GA akan melalui proses seleksi untuk memilih induk untuk proses crossover dan mutasi. Beberapa metode seleksi kromosom yaitu rank-based final assignment, roulette wheel selection, stochastic universal sampling, local selection, truncation selection (Saini, 2017).

Selanjutnya kromosom yang berhasil lulus seleksi akan melalui proses crossover dan dinamakan kromosom induk. Crossover adalah proses pindah silang nilai gen di antara kromosom induk. Kromosom hasil crossover disebut sebagai offspring. Setelah proses crossover, selanjutnya adalah proses mutasi kromosom offspring hasil crossover. Proses mutasi adalah mengganti satu gen yang terpilih secara acak dengan suatu nilai baru yang didapat secara acak. Setelah diperoleh kromosom baru hasil crossover dan mutasi, artinya telah dilakukan satu iterasi GA atau disebut satu generasi. Kromosom-kromosom lama akan digantikan dengan kromosom baru tanpa memperhatikan nilai fitness-nya. Proses selanjutnya adalah mengulang iterasi hingga sudah mencapai stopping criteria. Setelah melewati sekian iterasi (generasi) akan didapatkan individu terbaik.

Secara sederhana, berikut adalah pseudocode dari metode GA:

1. Definisikan fungsi fitness

2. $\mathrm{N}=$ stopping criteria

3. Representasi kromosom

4. Inisialisasi kromosom dalam populasi secara acak

5. Evaluasi kromosom dalam populasi

6. $\mathrm{t}=0$ while $\mathrm{t} \leq N$ \{ lakukan

a. Seleksi kromosom

b. Crossover kromosom

c. Mutasi kromosom

d. General Replacement 


$$
\begin{aligned}
& t=t+1 \\
& \}
\end{aligned}
$$

\section{Metode Pattern Search}

Pattern Search adalah metode optimasi yang memperbarui iterasi saat ini dengan mengambil sampel fungsi tujuan untuk menemukan penurunan nilai pada jumlah titik yang terbatas sepanjang ruang pencarian solusi (Yudong, Shuihua, Genlin, \& Zhengchao, 2013). Metode Pattern Search bekerja dengan baik untuk mencari solusi local optimum, yaitu solusi dalam suatu rentang tertentu yang terbatas. Misal $f$ menyatakan fungsi fitness, $x_{0}$ adalah titik tebakan awal, dan $\Delta_{0}$ adalah panjang langkah awal, metode PS akan terus membangkitkan iterasi sehingga $f\left(x_{k+1}\right) \leq$ $f\left(x_{k}\right)$. Setiap iterasi terdiri dari "Search-Step" dan "Poll-Step". Search-step membangkitkan sejumlah titik trial yang terbatas pada sebuah Mesh $M_{k}$, yang berpusat di $x_{k}$ dan didefinisikan oleh himpunan terbatas pattern $\Gamma$ yang dapat menjangkau ruang solusi. Mesh didefinisikan sebagai berikut:

$$
M_{k}(i)=\left\{x_{k}+\Delta_{k} d_{i}, \quad i \in \Gamma\right\} \quad \text { Pers. } 1
$$

Poll step adalah langkah untuk melakukan polling pada titik di mesh saat ini untuk menemukan titik terbaik. Poll step dikatakan lengkap bila semua titik dilakukan polling, dan dikatakan tidak lengkap bila algoritmanya berhenti ketika sudah menemukan titik yang nilai fungsi fitnesnya lebih kecil dibanding titik saat ini. Poll step yang lengkap memiliki kinerja yang lebih baik namun membutuhkan waktu computing yang lebih lama, sedangkan poll step yang tidak lengkap dapat menemukan local optimum.

Jika poll step menemukan titik yang lebih baik maka $x_{k+1}$ sama dengan titik baru, dan perbarui panjang langkah dengan mengalikan $\Delta_{k}$ dengan faktor ekspansi $\alpha_{e}$ sehingga $\Delta_{k+1}>$ $\Delta_{k}$ karena pattern saat ini adalah himpunan yang cocok untuk arah poll. Namun jika poll step tidak menemukan titik yang lebih baik maka $x_{k+1}=x_{k}$ dan kurangi panjang langkah dengan dengan mengalikan $\Delta_{k}$ dengan faktor kontraksi $\alpha_{c}(<1)$ sehingga $\Delta_{k+1}<\Delta_{k}$.

Berikut adalah pseudocode dari metode Pattern Search (PS) (Yudong, Shuihua, Genlin \& Zhengchao, 2013).
1. Inisialisasi: bangkitkan pattern $\Gamma$ dan panjang langkah $\Delta_{0}$

2. Ulangi langkah berikut hingga iterasi maksimum

a. Bangkitkan mesh baru $\left\{M_{k}\right\}$

b. Lakukan Poll step pada titik-titik di Mesh. Jika berhasil maka perluas Mesh, bila tidak maka persempit mesh.

\section{Formulasi Model Matematika}

Dalam melakukan penjadwalan mata kuliah dengan metode GA-PS, terdapat asumsiasumsi yang digunakan, di antaranya:

1. Mata kuliah dengan bobot 2 dan 3 sks dilaksanakan dalam 1 kali pertemuan/minggu.

2. Pelaksanaan mata kuliah wajib, diparalelkan menjadi $3-6$ kelas

3. Pelaksanaan kuliah dilaksanakan dari Senin-Jumat dengan 10 slot waktu/sesi dengan masing-masing slot berjumlah 45 menit. Perkuliahan dimulai pukul 08:0008.45 hingga 16:20-17:05, dan jam istirahat pukul 12:05-13:00. Pembagian slot waktu dapat dilihat pada Tabel 1.

Tabel 1. Pembagian slot waktu dalam 1 minggu

\begin{tabular}{|c|c|c|c|c|}
\hline No & Slot waktu & Senin & $\ldots$ & Jumat \\
\hline 1 & $08: 00-08: 45$ & & & \\
\hline 2 & $08: 50-09: 35$ & & & \\
\hline. & & & & \\
\hline. & & & & \\
\hline. & & & & \\
\hline 10 & $16: 20-17: 05$ & & & \\
\hline
\end{tabular}

4. Mata kuliah yang berbobot 2 sks mengisi 2 slot waktu (95 menit), sedangkan mata kuliah dengan bobot 3 sks mengisi 3 slot waktu (145 menit)

5. Diasumsikan jumlah peserta kelas sudah di-assign sebelum dilakukan penjadwalan

6. Kendala yang digunakan dalam penjadwalan adalah kendala mutlak (hard constraint), di antaranya:

a. Dosen tidak dapat mengajar dua mata kuliah di waktu yang sama

b. Satu ruangan hanya untuk satu mata kuliah

c. Mahasiswa angkatan berapa pun tidak dapat mengambil dua mata kuliah dengan kode MK berbeda di waktu yang sama. Namun dua 
mata kuliah dengan kode MK yang sama dapat berjalan dalam waktu yang sama.

d. Jumlah peserta kelas setiap mata kuliah yang di-assign ke dalam ruangan, harus lebih kecil atau sama dengan kapasitas ruangan

e. Setiap mata kuliah harus berjalan secara kontinu tanpa ada break. Artinya mata kuliah dengan bobot 2 sks, harus mengisi 2 slot waktu secara kontinu, sedangkan untuk mata kuliah dengan bobot 3 sks, harus mengisi 3 slot waktu secara kontinu.

Fungsi fitness dari masalah penjadwalan yang dipakai dalam penelitian ini, yaitu memaksimumkan preferensi dosen mengajar pada jam, hari dan ruangan yang diinginkan, memaksimumkan kapasitas ruangan untuk setiap mata kuliah dan meminimumkan mata kuliah yang di-assign pada waktu yang tidak diinginkan (Balcilar, 2020). Selanjutnya, fungsi fitness dan kendala mutlak dimodelkan ke dalam persamaan matematika untuk memudahkan pengkodean ke dalam program GA-PS. Misal:

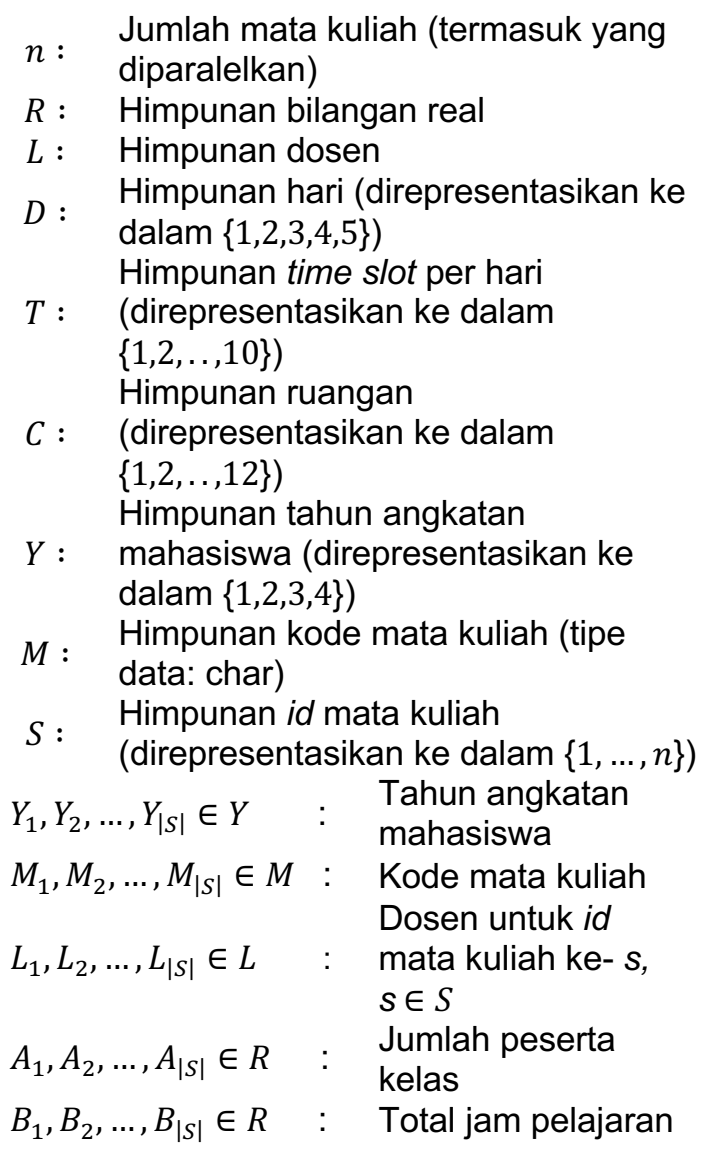

$$
\begin{aligned}
& \text { Ruangan yang } \\
& C p_{1}, C p_{2}, \ldots, C p_{|S|} \in C: \quad \text { diinginkan dosen } \\
& \text { untuk id mata kuliah } \\
& \text { ke- } s, s \in S \\
& \text { Hari yang diinginkan } \\
& D p_{1}, D p_{2}, \ldots, D p_{|S|} \in D \quad \text { dosen untuk id mata } \\
& \text { kuliah ke- } s, s \in S \\
& \text { Slot time yang } \\
& T p_{1}, T p_{2}, \ldots, T p_{|S|} \in T: \quad \text { diinginkan dosen } \\
& \text { untuk id mata kuliah } \\
& \text { ke- } s, s \in S \\
& \text { Gain yang diperoleh } \\
& \text { mata kuliah bila di- } \\
& E p_{1}, E p_{2}, \ldots, E p_{|S|} \in R: \quad \begin{array}{l}
\text { assign pada } \\
\text { ruangan, hari dan }
\end{array} \\
& \text { slot waktu yang } \\
& \text { diinginkan dosen } \\
& \text { Penalty yang } \\
& \text { diperoleh mata } \\
& P_{d, t} \in R \quad \text { : kuliah bila di-assign } \\
& \text { pada hari ke- } d \text { dan } \\
& \text { slot waktu ke-t } \\
& C t_{1}, C t_{2}, \ldots, C t_{|C|} \in C: \quad \text { Kapasitas ruangan } \\
& \text { ke- } c, c \in C
\end{aligned}
$$

Definisikan $X_{d, t, c, s} \in\{0,1\}$, dimana $X_{d, t, c, s}=$ 1 jika id mata kuliah $s$ di assign pada hari $d$, slot waktu $t$, dan ruangan $c$, dan $X_{d, t, c, s}=$ 0 sebaliknya. Sehingga masalah penjadwalan mata kuliah dapat dimodelkan ke dalam persamaan matematis berikut:

$\operatorname{Min} Z=-\sum_{i=1}^{|S|} A_{i} \cdot E p_{i} \cdot X_{D p_{i}, T p_{i}, C p_{i}, i}-$ $\sum_{d=1}^{|D|} \sum_{t=1}^{|T|} \sum_{c=1}^{|C|} \sum_{S=1}^{|S|}\left(C t_{c}-A_{S}\right) \cdot X_{d, t, c, s}+$ $\sum_{d=1}^{|D|} \sum_{t=1}^{|T|} \sum_{c=1}^{|C|} \sum_{S=1}^{|S|} P_{d, t} \cdot A_{s} \cdot X_{d, t, c, s}$

Terhadap kendala mutlak :

(2) $\sum_{c=1}^{|C|} \sum_{S=1}^{|S|} X_{d, t, c, s}=1$, jika $L_{s}=$ $L_{l},\{\forall s \in S, \forall l \in L, \forall d \in D$, $\forall t \in T\}$

(3) $\sum_{s=1}^{|S|} X_{d, t, c, s}=1,\{\forall d \in D, \forall d \in D, \forall c \in$ C\}

(4) $\sum_{C=1}^{|C|} \sum_{S=1}^{|S|} X_{d, t, c, S}=1$, jika $M_{i}$ unik dan $Y_{s}=Y_{y},\{\forall s \in$ $S, \forall y \in Y, \forall d \in D, \forall t \in T\}$

(5) $X_{d, t, c, s} \cdot A_{s} \leq C t_{c},\{\forall d \in D, \forall t \in$ $T, \forall c \in C, \forall s \in S\}$

(6) $\sum_{o=j+1}^{j+B_{s}-1} X_{d, t, c, s}=B_{i}-1$, jika $\left(\begin{array}{c}j=\text { slot waktu dimulainya mata kuliah s } \\ d=\text { hari mata kuliah s } \\ c=\text { ruangan mata kuliah s }\end{array}\right)$,

$\{\forall s \in S\}$ 
Tabel 2. Daftar mata kuliah

\begin{tabular}{|c|c|c|c|c|c|c|c|c|c|c|c|}
\hline $\begin{array}{c}\text { Id } \\
\text { MK }\end{array}$ & Tahun & $\begin{array}{c}\text { Kelas } \\
\text { Paralel }\end{array}$ & $\begin{array}{c}\text { Kode } \\
\text { MK }\end{array}$ & $\begin{array}{c}\text { Mata } \\
\text { Kuliah }\end{array}$ & sks & Dosen & Mhs & $\begin{array}{c}\text { Preferensi } \\
\text { Ruangan } \\
\mathbf{( 1 , . . 1 2 )}\end{array}$ & $\begin{array}{c}\text { Preferensi } \\
\text { Hari } \\
\mathbf{( 1 , . . 5 )}\end{array}$ & $\begin{array}{c}\text { Preferensi } \\
\text { Time Slot } \\
\mathbf{( 1 , . . 1 0 )}\end{array}$ & $\begin{array}{c}\text { Gain } \\
\mathbf{( 0 , 1}]\end{array}$ \\
\hline 1 & 1 & A & IUM341 & MK 1 & 3 & AA & 35 & 1 & 1 & 2 & 0.5 \\
\hline 2 & 1 & B & IUM341 & MK 2 & 3 & BB & 23 & 3 & 4 & & 0,3 \\
\hline 3 & 1 & C & IUM341 & MK 3 & 3 & CC & 40 & & 5 & 9 & 0,9 \\
\hline \multicolumn{7}{|l}{ dan seterusnya } \\
\hline
\end{tabular}

\section{Pengolahan Data}

Data yang digunakan sebagai studi kasus untuk penelitian ini adalah data mata kuliah semester Genap 2019/2020 Jurusan Teknik Industri Universitas Trisakti. Jumlah mata kuliah yang perlu dijadwalkan adalah 93, dengan 12 jumlah ruangan dan 10 slot waktu dalam sehari. Tabel 2 adalah input data penjadwalan mata kuliah untuk pengkodean dengan metode GAPS. Sedangkan Tabel 3 adalah data nama ruangan dan kapasitasnya.

Pada Tabel 2 terdapat kolom untuk mengisi preferensi ruangan, hari dan time slot yang diinginkan oleh dosen. Misal untuk mata kuliah 1 , pengajar A memilih ruang 1, hari ke-1 (Senin) dan time slot 2 (mulai pukul 08.50), maka gain mata kuliah ini bila di-assign sesuai dengan preferensi akan bernilai 0.5 . Nilai Gain bernilai random dalam selang $(0,1]$, artinya nilai gain tidak boleh 0 bila seorang dosen memiliki preferensi (baik ruangan/hari/time slot), dan nilai maksimum gain adalah 1 .

Selanjutnya, Tabel 4 dijadikan input data untuk menjelaskan nilai penalty untuk setiap slot waktu. Misal pada jam 08:00-08:45 diberikan nilai penalty 0,5 bila mata kuliah diassign pada slot waktu tersebut, dan misal pada jam 16:20-17:05 diberikan nilai penalty 1 yang artinya sebisa mungkin mata kuliah tidak diassign pada slot waktu terakhir tersebut.

Tabel 3. Data ruangan dan kapasitasnya

\begin{tabular}{|c|c|}
\hline Kode Ruang & Kapasitas \\
\hline 615 & 25 \\
\hline 616 & 42 \\
\hline dan seterusnya \\
\hline
\end{tabular}

Tabel 4. Data penalty slot waktu

\begin{tabular}{|c|c|c|c|}
\hline Slot Waktu & Senin & $\ldots$ & Jumat \\
\hline $08: 00-08: 45$ & 0,5 & & 0,5 \\
\hline $08: 50-09: 35$ & 0 & & 0 \\
\hline$\ldots$ & & & \\
\hline $16: 20-17: 05$ & 1 & & 1 \\
\hline
\end{tabular}

\section{Metode Hybrid GA-PS}

Pada penelitian ini, sebelum menerapkan metode Hybrid GA-PS, jumlah kemungkinan dari seluruh mata kuliah untuk di-assign pada hari, slot waktu dan ruangan yang memenuhi seluruh hard constraint akan dihitung terlebih dahulu. Selanjutnya metode GA-PS akan diterapkan untuk memilih peluang assignment terbaik yang akan di-assign ke mata kuliah tersebut. Gambar 1 menunjukkan flowchart dari metode hybrid GA-PS dalam penelitian ini.

Berikut adalah penjelasan dari penyusunan algoritma GA-PS untuk menyelesaikan masalah penjadwalan mata kuliah.

\section{Menentukan parameter GA-PS}

Pada penelitian ini, parameter metode hybrid GA-PS yang dipakai sesuai pada Tabel 5.

Tabel 5. Parameter metode GA-PS

\begin{tabular}{|l|c|}
\hline \multicolumn{1}{|c|}{ Parameter GA } & Nilai \\
\hline Ukuran Populasi & 500 \\
\hline Iterasi Maksimum & 250 \\
\hline Crossover & Scattered \\
\hline $\begin{array}{l}\text { Probabilitas Mutasi } \\
\text { (Pm) }\end{array}$ & 0,01 \\
\hline Rate Elitisme & $5 \%$ \\
\hline Stall Generation & 50 \\
\hline Selection & Stochastic Uniform \\
\hline \multicolumn{1}{|c|}{ Parameter PS } & 1 \\
\hline Initial Mesh Size & Nilai \\
\hline $\begin{array}{l}\text { Max Function } \\
\text { Evaluations }\end{array}$ & $2000^{*}$ numberOfVariables \\
\hline Max Iterations & $100^{*}$ numberOfVariables \\
\hline $\begin{array}{l}\text { Mesh Contraction } \\
\text { Factor }\end{array}$ & 0,5 \\
\hline $\begin{array}{l}\text { Mesh Expansion } \\
\text { Factor }\end{array}$ & 2 \\
\hline
\end{tabular}

Dasar pemilihan parameter seperti tabel 5 adalah karena simulasi yang dilakukan sudah mencoba beberapa kombinasi nilai parameter, seperti mengubah nilai pm $(0.01 ; 0.05 ; 0.1$; 


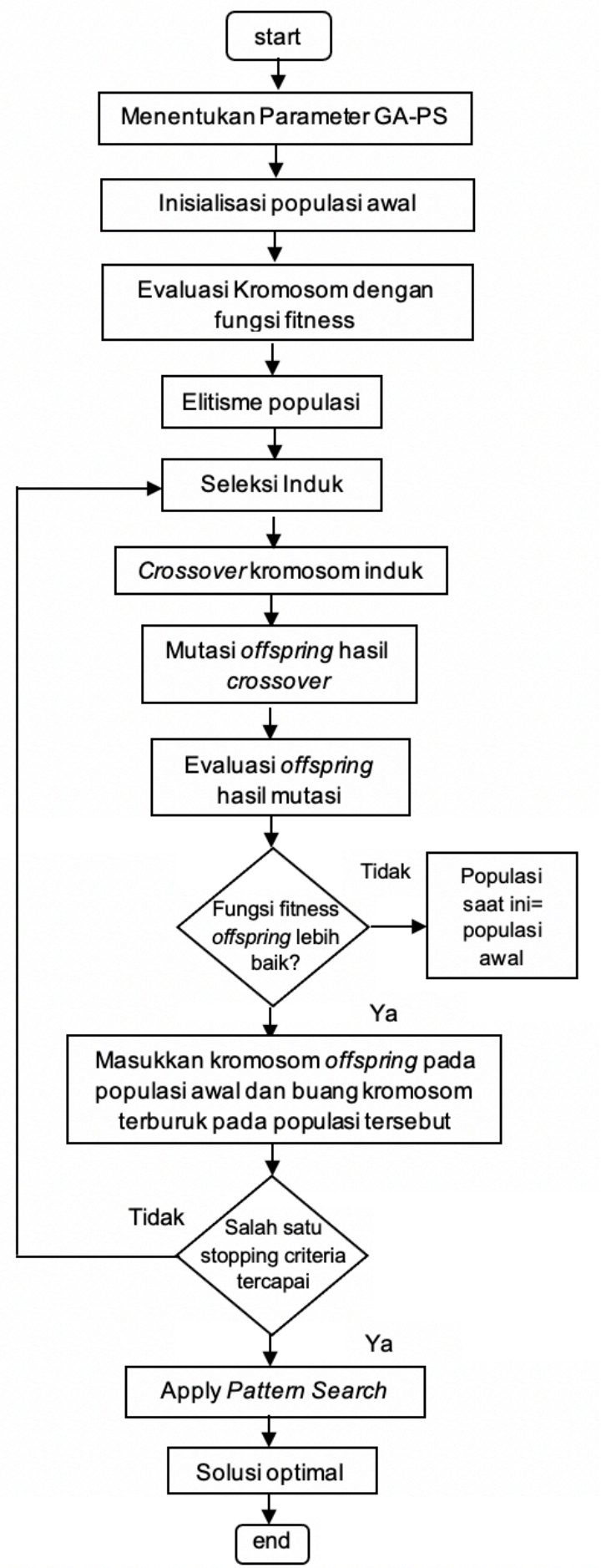

Gambar 1. Flowchart metode hybrid GA-PS

$0,15)$ dan mengubah rate elitisme $(5 \% ; 10 \%)$, diperoleh kombinasi parameter yang memberikan solusi terbaik untuk masalah penjadwalan mata kuliah adalah nilai $p m 0.01$ dan rate elitisme $5 \%$.

\section{Representasi kromosom}

Dalam penelitian ini, untuk mendekati masalah nyata sistem penjadwalan mata kuliah, tipe kromosom yang digunakan adalah suatu variabel yang mencakup ruang kuliah, time slot, dosen, mata kuliah, definisikan $X_{d, t, c, s} \in\{0,1\}$, dimana $X_{d, t, c, s}=1$ jika dan hanya jika id mata kuliah $s$ di-assign pada hari $d$, slot waktu $t$, dan ruangan $c$, dan $X_{d, t, c, s}=0$ sebaliknya jika dan hanya jika id mata kuliah $s$ tidak di-assign pada hari $d$, slot waktu $t$, dan ruangan $c$.

\section{Inisialisasi populasi}

Matriks mata kuliah, matriks bentrok, matriks preferensi dosen, matriks slot waktu, matriks ruangan, dan matriks assignment awal digunakan sebagai input untuk menghitung jumlah kemungkinan dari seluruh mata kuliah untuk di-assign pada hari, slot waktu dan ruangan yang memenuhi seluruh hard constraint.

Matriks bentrok adalah $M_{n \times n}$ dimana $n$ adalah jumlah mata kuliah yang harus dijadwalkan. Elemen matriks bentrok bernilai biner, bernilai 1 bila 'bentrok' dan bernilai 0 bila 'tidak bentrok'. Matriks Assignment $A_{|T| \times|C|}$ adalah representasi dari sebuah solusi metode GA-PS yaitu berupa jadwal yang optimal, dengan $|T|$ adalah slot waktu dalam seminggu dan $|C|$ adalah ruangan. Elemen dari matriks tersebut adalah id mata kuliah bila di-assign pada slot waktu $i$ dan ruangan $j$, sedangkan bilangan 0 artinya pada slot waktu $i$ dan ruangan $j$ tidak di-assign mata kuliah. Sedangkan matriks assignment awal seluruh elemennya bernilai 0 . Tabel 6 merupakan contoh bentuk representasi jadwal ke dalam bentuk matriks.

Tabel 6. Contoh representasi jadwal dalam bentuk matriks assignment

\begin{tabular}{|c|c|c|c|}
\hline Waktu/Ruang & $\mathbf{1}$ & $\ldots$ & $\mathbf{1 2}$ \\
\hline $\mathbf{1}$ & 90 & & 0 \\
\hline $\mathbf{2}$ & 55 & & 80 \\
\hline$\ldots$ & & & \\
\hline$\ldots$ & & & \\
\hline $\mathbf{5 0}$ & 0 & & 5 \\
\hline
\end{tabular}

Setelah mendefinisikan matriks-matriks input tersebut, hitung seluruh kemungkinan assign untuk seluruh mata kuliah. Misal untuk mata kuliah MK 1 terdapat 100 kemungkinan assign, MK 2 terdapat 180 kemungkinan assign, dan seterusnya. Selanjutnya bangkitkan populasi awal dengan uniform random, kromosom awal ini bernilai [0 1] yang terdistribusi secara uniform. Setelah itu, kalikan setiap nilai kromosom awal tersebut pada jumlah 
kemungkinan assign seluruh mata kuliah. Berikut adalah contoh kromosom awal:

\begin{tabular}{|c|c|c|c|}
\hline gen 1 & $\ldots$ & $\ldots$ & gen 93 \\
\hline 0.199 & & & 0.739 \\
\hline
\end{tabular}

Misal untuk mata kuliah pertama yaitu MK 1 terdapat 100 kemungkinan assign, karena nilai gen 1 bernilai 0.199 maka kita harus memilih kemungkinan assign ke $100 \times 0.199=19.9 \approx$ 20, misal untuk mata kuliah ke 93 yaitu MK 93 terdapat 350 kemungkinan assign, karena nilai gen 93 bernilai 0.739 maka kita harus memilih kemungkinan assign ke $350 \times 0.739=$ $258.65 \approx 259$, dan seterusnya untuk semua mata kuliah dilakukan perhitungan jumlah kemungkinan assignnya pada nilai gen pada kromosom. Bila nilai gen bernilai nol maka pilih kemungkinan assign yang pertama dari list, sedangkan bila gen bernilai 1 maka pilih kemungkinan assign yang paling terakhir dari list.

\section{Evaluasi populasi awal}

Setelah semua mata kuliah dihitung kemungkinan assignnya berdasarkan nilai kromosom populasi awal, selanjutnya adalah menghitung nilai fitness dari setiap kemungkinan assign yang dipilih tersebut dengan membuat nilai kromosom yang berkaitan bernilai 1 bila sesuai dengan preferensi, sedangkan yang tidak sesuai preferensi bernilai 0 . Evaluasi populasi dihitung dengan fungsi fitness berdasarkan persamaan 1

\section{Elitisme populasi}

Proses elitisme dilakukan dengan mengcopy kromosom-kromosom terbaik agar tidak hilang saat proses crossover dan mutasi. Rate elitism yang dipakai sebesar $5 \%$ artinya 5 kromosom terbaik dipilih dari total $\mathrm{N}$ jumlah kromosom, dan di-copy ke dalam populasi.

\section{Seleksi}

Selanjutnya dilakukan seleksi induk yaitu dengan memilih dua kromosom dengan metode default stochastic uniform. Dua kromosom inilah yang akan menjadi induk untuk melakukan proses crossover.

\section{Crossover dan mutasi}

Crossover atau pindah silang dalam penelitian ini dilakukan dengan crossover scattered. Hasil crossover gen-gen dari induk ini akan diturunkan pada keturunannya (offspring). Tahapan selanjutnya adalah melakukan proses mutasi untuk offspring yang diperoleh dari proses crossover. Proses mutasi adalah mengganti nilai gen dari suatu kromosom dengan suatu nilai yang diperoleh secara random. Dalam penelitian ini mutasi dilakukan dengan uniform mutation dengan nilai $p m=0.01$ artinya $1 \%$ gen offspring mengalami mutasi.

\section{Evaluasi kromosom offspring}

Setelah proses mutasi dilakukan, bila nilai fitness kromosom offspring hasil mutasi lebih baik, maka akan masuk pada popolasi awal menggantikan kromosom terburuk dalam popolasi tersebut, sedangkan bila kromosom hasil mutasi buruk, maka akan dibuang dan populasi saat ini tetaplah sama dengan populasi awal.

\section{Pemeriksaan stopping criteria}

Proses dari seleksi induk hingga mutasi disebut sebagai satu generasi, selanjutnya populasi akan terus melanjutkan generasi hingga salah satu stopping criteria tercapai, yaitu ketika jumlah iterasinya sudah maksimum atau ketika stall generation sudah tercapai.

\section{Apply metode Pattern Search (PS)}

Metode GA dapat dengan cepat mencapai nilai minimum lokal, tetapi membutuhkan banyak evaluasi fungsi untuk mencapai konvergensi. Agar mempercepat proses solusi tersebut, maka setelah metode GA menyelesaikan beberapa generasi untuk mendekati titik optimal, selanjutnya gunakan solusi GA sebagai titik awal untuk metode Pattern Search untuk melakukan pencarian lokal yang lebih cepat dan lebih efisien. Ketika metode GA berhenti karena telah mencapai stopping criteria (jumlah iterasi maksimum atau stall generation tercapai), selanjutnya perhitungan dilakukan oleh metode PS. Setelah kedua syarat stopping criteria tercapai maka akan dihasilkan output berupa kromosom optimal yang akan menghasilkan nilai fitness paling baik bila dikalikan dengan kemungkinan assign seluruh mata kuliah.

\section{Hasil dan Pembahasan}

Simulasi penyelesaian penjadwalan mata kuliah dengan metode Hybrid GA-PS dikodekan 
pada Matlab. Pertama, metode GA biasa tanpa hybrid diterapkan pada permasalahan penjadwalan, selanjutnya metode Hybrid GAPS diterapkan untuk menjadi perbandingan. Kedua metode ini dibandingkan dengan menggunakan parameter yang sama sesuai dengan Tabel 6 . Setelah dilakukan sebanyak 10 kali simulasi untuk setiap metode, hasil dari running program dapat dilihat pada Tabel 7 .

Dapat dilihat pada Tabel 7, setelah 10 kali simulasi dilakukan, metode Hybrid GA-PS bekerja lebih baik dibandingkan metode GA tanpa hybrid, hal ini terbukti dari nilai rataan fitness value metode hybrid GA-PS yang lebih baik yaitu $-3528,62$ dan $99,24 \%$ solusi tercapai. Persen solusi ini menyatakan jumlah mata kuliah yang di-assign pada hari, slot waktu dan ruangan , yang artinya 99,24\% dari 93 jumlah mata kuliah berhasil di-assign, sedangkan metode GA tanpa hybrid hanya mampu mencapai solusi sekitar $65 \%$ dan rataan fitness value sebesar $-3100,76$. Fungsi fitness dari solusi bernilai negatif karena fungsi fitness dalam bentuk minimisasi, artinya bila nilai fungsi fitness semakin negatif maka semakin baik merepresentasikan solusi yang memenuhi setiap kendala.

Gambar 2 adalah salah satu hasil running metode GA tanpa hybrid dengan nilai fitness yang diperoleh adalah -2731. Hasil simulasi dari metode GA tanpa hybrid menghasilkan hanya $52 \%$ atau 49 dari 93 mata kuliah yang berhasil di assign.

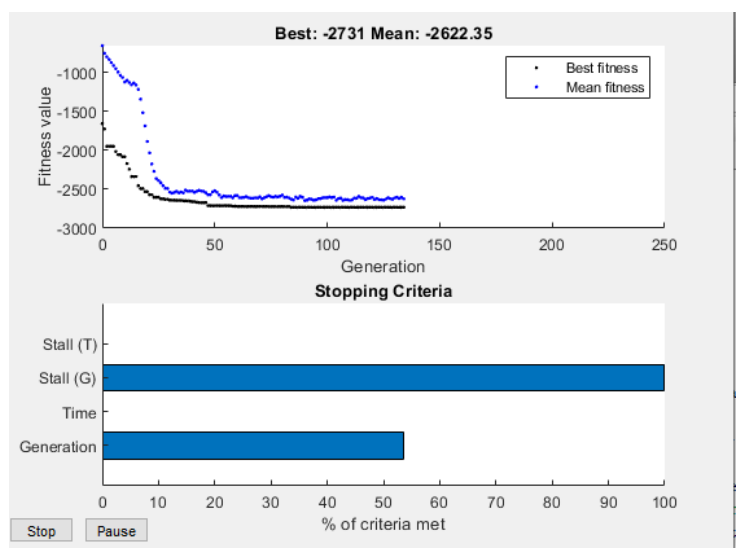

Gambar 2. Hasil running metode GA tanpa hybrid

Hal ini menunjukkan bahwa metode GA tanpa hybrid kurang cocok untuk menyelesaikan masalah penjadwalan dengan fungsi tujuan yang multiobjektif. Ini dikarenakan metode GA biasa hanya bekerja baik untuk mencari solusi global optimum dan kurang baik mencari solusi local optimum. Cara lain agar metode GA tanpa hybrid menghasilkan solusi yang lebih akurat adalah dengan mengubah atau menambah stopping criteria, namun hal ini memerlukan banyak evaluasi fungsi fitness untuk mendekati global optimum, yang otomatis juga memerlukan waktu komputasi yang lebih lama.

Karena kekurangan metode GA tersebut, metode PS di hybridkan pada metode GA untuk dapat melakukan pencarian nilai local optimum. Metode PS diterapkan ketika metode GA berhenti karena salah satu stopping criteria tercapai.

Tabel 7. Tabel perbandingan metode GA tanpa hybrid dan metode hybrid GA-PS

\begin{tabular}{|c|c|c|c|c|c|}
\hline \multicolumn{3}{|c|}{ Metode GA Tanpa Hybrid } & \multicolumn{3}{c|}{ Metode Hybrid GA-PS } \\
\hline Simulasi ke- & Fitness Value & \% Solusi & Simulasi ke- & Fitness Value & \% Solusi \\
\hline 1 & -3049 & 52,6882 & 1 & -3757 & 100 \\
\hline 2 & -3860 & 97,8495 & 2 & $-3337,5$ & 100 \\
\hline 3 & -2800 & 45,1613 & 3 & $-3539,5$ & 98,9247 \\
\hline 4 & $-3793,5$ & 98,9247 & 4 & $-3452,5$ & 98,9247 \\
\hline 5 & $-2954,5$ & 52,6882 & 5 & -3552 & 98,9247 \\
\hline 6 & $-3371,6$ & 97,8495 & 6 & $-3630,5$ & 97,8495 \\
\hline 7 & -2740 & 52,6882 & 7 & -3658 & 100 \\
\hline 8 & -2864 & 52,6882 & 8 & -3469 & 100 \\
\hline 9 & -2844 & 52,6882 & 9 & $-3448,6$ & 98,9247 \\
\hline 10 & -2731 & 52,6882 & 10 & $-3441,6$ & 98,9247 \\
\hline Rataan & $-3100,76$ & $\mathbf{6 5 , 5 9 1 4}$ & Rataan & $\mathbf{- 3 5 2 8 , 6 2}$ & $\mathbf{9 9 , 2 4 7 3}$ \\
\hline
\end{tabular}


Gambar 3 menunjukkan hasil simulasi menggunakan metode hybrid GA-PS dengan fitness value sebesar -3757 . Metode Hybrid GA-PS ini mampu memberikan solusi $100 \%$ atau 93 dari 93 mata kuliah berhasil di assign. Hal ini menunjukkan bahwa metode GA-PS mampu memberikan solusi yang lebih baik dan efisien.

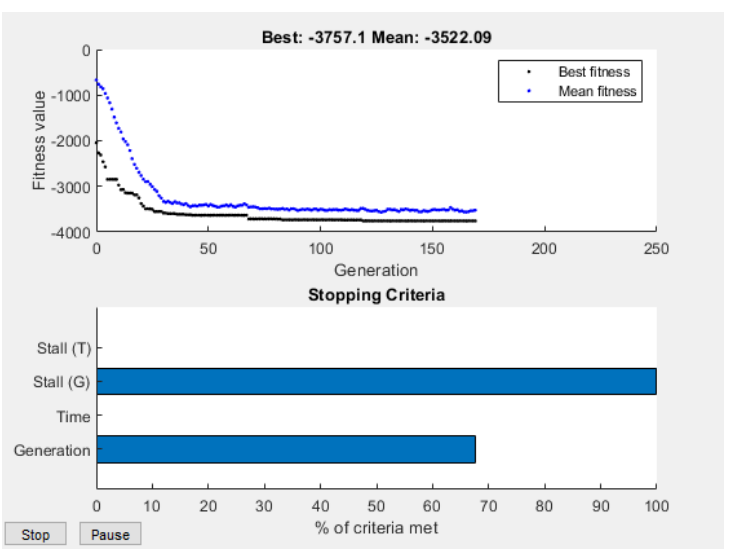

Gambar 3. Hasil running metode Hybrid GA-PS

Matriks Assignment optimal dapat dilihat pada Tabel 8. Matriks Assignment $A_{50 \times 12}$ ini menjadi representasi dari sebuah solusi metode GA-PS yaitu berupa jadwal yang optimal. Dari matriks tersebut, 93 jumlah mata kuliah atau $100 \%$ mata kuliah berhasil di assign pada slot waktu dan ruangan masing-masing. Hal ini menunjukkan bahwa metode hybrid GA-PS telah berhasil menghasilkan output berupa jadwal yang optimal.

Tabel 9 adalah jadwal optimal hasil running simulasi metode GA-PS yang telah diubah ke dalam bentuk tabel penjadwalan. Dapat dilihat pada tabel tersebut bahwa pada slot waktu pada jam 08.00-08:45 yang diberikan nilai penalty 0,5, dan jam 16:20-17:05 yang diberikan nilai penalty 1 masih terdapat beberapa mata kuliah yang di assign. Begitu pun dengan masih terdapat beberapa mata kuliah yang di-assign tidak sesuai dengan preferensi dosen. Faktor yang menyebabkan jadwal tidak ideal seperti yang diinginkan adalah karena banyaknya mata kuliah yang harus dijadwalkan, sehingga perlu melonggarkan beberapa kendala atau fungsi tujuan.

\section{Kesimpulan}

Berdasarkan hasil model penjadwalan menggunakan metode Hybrid Genetic Algorithm Pattern Search dengan bantuan
Tabel 8. Matriks Assignment Optima

\begin{tabular}{|c|c|c|c|c|c|c|c|c|c|c|}
\hline 2 & 32 & 55 & 0 & 34 & 1 & 0 & 82 & 31 & 0 & 0 \\
\hline 2 & 32 & 55 & 0 & 34 & 1 & 0 & 82 & 31 & 0 & 0 \\
\hline 2 & 36 & 55 & 39 & 0 & 1 & 0 & 82 & 0 & 0 & 0 \\
\hline 4 & 36 & 37 & 39 & 35 & 86 & 0 & 57 & 0 & 0 & 56 \\
\hline 4 & 36 & 37 & 39 & 35 & 86 & 0 & 57 & 0 & 0 & 56 \\
\hline 4 & 0 & 37 & 0 & 35 & 86 & 0 & 57 & 58 & 0 & 56 \\
\hline 0 & 7 & 8 & 0 & 40 & 6 & 0 & 43 & 58 & 0 & 87 \\
\hline 0 & 7 & 8 & 0 & 40 & 6 & 0 & 43 & 58 & 0 & 87 \\
\hline 0 & 7 & 8 & 0 & 40 & 6 & 0 & 43 & 0 & 0 & 87 \\
\hline 0 & 0 & 0 & 0 & 0 & 0 & 0 & 0 & 0 & 0 & 0 \\
\hline 47 & 11 & 45 & 49 & 46 & 60 & 0 & 62 & 0 & 0 & 0 \\
\hline 47 & 11 & 45 & 49 & 46 & 60 & 0 & 62 & 0 & 0 & 0 \\
\hline 0 & 11 & 0 & 0 & 50 & 60 & 0 & 62 & 52 & 0 & 89 \\
\hline 13 & 14 & 0 & 16 & 50 & 65 & 66 & 68 & 52 & 0 & 89 \\
\hline 13 & 14 & 15 & 16 & 50 & 65 & 66 & 68 & 52 & 0 & 89 \\
\hline 13 & 14 & 15 & 16 & 0 & 65 & 66 & 68 & 0 & 0 & 0 \\
\hline 0 & 90 & 15 & 0 & 0 & 0 & 0 & 0 & 0 & 0 & 0 \\
\hline 0 & 90 & 17 & 0 & 0 & 0 & 0 & 44 & 71 & 0 & 70 \\
\hline 0 & 90 & 17 & 0 & 0 & 0 & 0 & 44 & 71 & 0 & 70 \\
\hline 0 & 0 & 17 & 0 & 0 & 0 & 0 & 44 & 0 & 0 & 0 \\
\hline 0 & 0 & 0 & 30 & 0 & 0 & 0 & 76 & 0 & 0 & 91 \\
\hline 0 & 0 & 3 & 30 & 0 & 0 & 0 & 76 & 0 & 0 & 91 \\
\hline 0 & 54 & 3 & 0 & 0 & 0 & 0 & 63 & 0 & 0 & 91 \\
\hline 0 & 54 & 3 & 0 & 0 & 0 & 0 & 63 & 0 & 0 & 83 \\
\hline 0 & 54 & 0 & 0 & 0 & 0 & 0 & 63 & 0 & 0 & 83 \\
\hline 0 & 41 & 61 & 0 & 0 & 0 & 0 & 0 & 0 & 0 & 83 \\
\hline 0 & 41 & 61 & 0 & 59 & 88 & 0 & 12 & 0 & 0 & 42 \\
\hline 0 & 41 & 61 & 0 & 59 & 88 & 0 & 12 & 0 & 0 & 42 \\
\hline 0 & 0 & 0 & 0 & 59 & 88 & 0 & 12 & 0 & 0 & 42 \\
\hline 0 & 0 & 0 & 0 & 0 & 0 & 0 & 0 & 0 & 0 & 0 \\
\hline 0 & 0 & 0 & 0 & 25 & 0 & 0 & 73 & 0 & 0 & 0 \\
\hline$\hat{0}$ & $\hat{0}$ & $\hat{92}$ & $\hat{0}$ & $\approx 0$ & $\hat{0}$ & $\hat{0}$ & $\hat{51}$ & 30 & $\hat{0}$ & $6 \hat{7}$ \\
\hline 0 & 0 & 92 & 0 & 0 & 38 & 0 & 0 & 0 & 0 & 0 \\
\hline 0 & 78 & 92 & 0 & 0 & 38 & 0 & 77 & 0 & 0 & 0 \\
\hline 0 & 78 & 0 & 0 & 0 & 38 & 0 & 77 & 0 & 0 & 84 \\
\hline 0 & 0 & 0 & 0 & 0 & 0 & 0 & 75 & 0 & 0 & 84 \\
\hline 0 & 0 & 0 & 0 & 0 & 0 & 0 & 75 & 0 & 0 & 84 \\
\hline 0 & 0 & 0 & 0 & 64 & 0 & 0 & 5 & 0 & 0 & 0 \\
\hline 0 & 0 & 0 & 0 & 64 & 0 & 0 & 5 & 81 & 0 & 0 \\
\hline 0 & 0 & 0 & 0 & 64 & 0 & 0 & 5 & 81 & 0 & 0 \\
\hline 0 & 21 & 23 & 48 & 0 & 0 & 0 & 24 & 81 & 0 & 0 \\
\hline 0 & 21 & 23 & 48 & 80 & 0 & 0 & 24 & 0 & 0 & 0 \\
\hline 0 & 21 & 23 & 0 & 80 & 0 & 0 & 24 & 79 & 0 & 53 \\
\hline 0 & 0 & 0 & 0 & 80 & 0 & 0 & 18 & 79 & 0 & 53 \\
\hline 0 & 0 & 85 & 0 & 74 & 72 & 0 & 18 & 0 & 0 & 53 \\
\hline 0 & 0 & 85 & 0 & 74 & 72 & 0 & 18 & 29 & 0 & 28 \\
\hline 0 & 0 & 85 & 0 & 0 & 0 & 0 & 0 & 29 & 0 & 28 \\
\hline
\end{tabular}

software Matlab, diperoleh kesimpulan bahwa hasil 10 kali simulasi menunjukkan bahwa metode Hybrid GA-PS bekerja lebih baik dibandingkan metode GA tanpa hybrid untuk masalah penjadwalan mata kuliah, hal ini terbukti dari nilai rataan fitness value metode hybrid GA-PS yang lebih minimum dan persen solusi yang mendekati $100 \%$ mata kuliah terjadwalkan. Sedangkan metode GA tanpa hybrid PS hanya mampu mencapai solusi sekitar $65 \%$ dan memiliki nilai rataan fitness value yang tidak lebih baik dibanding metode Hybrid GA-PS. Nilai fungsi fitness dalam penelitian ini bernilai negatif, dikarenakan fungsinya dalam bentuk minimasi, artinya semakin kecil nilai fungsi fitness maka semakin baik memperoleh solusi yang memenuhi fungsi tujuan dan kendala. Namun, terdapat beberapa mata kuliah yang tidak sesuai dengan preferensi dosen dan slot waktu yang dihindari. Faktor yang menyebabkan jadwal tidak ideal seperti yang diinginkan adalah karena banyaknya mata kuliah yang harus dijadwalkan, sehingga perlu melonggarkan beberapa kendala atau fungsi tujuan. 
Tabel 9. Jadwal optimal hasil metode hybrid GA-PS

\begin{tabular}{|c|c|c|c|c|}
\hline $\begin{array}{c}\text { Slot } \\
\text { waktu }\end{array}$ & Senin & ... & $\cdots$ & Jumat \\
\hline $\begin{array}{c}08: 00- \\
08: 45\end{array}$ & $\begin{array}{l}\text { IUM341-B- Dr. Dadang ,M.T.-R615 } \\
\text { IIS204-C- Prof Parwadi ,Ph.D.-R616 } \\
\text { IIS321-A- Winnie,S.T., M.Si.-R618 } \\
\text { IIS204-E- Ramly,--R620 } \\
\text { IUM341-A- Fani,S.Si., M.Si.-R621 } \\
\text { IIP326-- Dr. Ir. Iveline,M.T.-R713 } \\
\text { IIS204-B- Linda,S.T., M.T.-R714 }\end{array}$ & & & $\begin{array}{l}\text { IUK301-B- Agung,S.T., M.T.-R620 } \\
\text { IIG305-A- Novia,S.T., M.T.-R713 }\end{array}$ \\
\hline & & & & \\
\hline $\begin{array}{l}15: 30- \\
16: 15\end{array}$ & $\begin{array}{l}\text { IIG305-C- Indah,S.Pd., M.Si.-R616 } \\
\text { IIG305-D- Nilla,S.T., M.T.-R618 } \\
\text { IIP324-A- Ir. Wawan,M.T.-R620 } \\
\text { IIG305-B- ARNES,S.T., M.Sc.-R621 } \\
\text { IIP324-D- Dr. Ir. Tri,M.M.-R713 } \\
\text { IIO305-- Dr. Dadan,--R716 } \\
\text { IIU201-A- Dr. Tiena,-R717 }\end{array}$ & & & $\begin{array}{l}\text { IIO304-- Imam,-R618 } \\
\text { IIP227-C- Linda,S.T., M.T.-R620 } \\
\text { IIP227-A- Dr. Ir. Nora,M.T.-R621 } \\
\text { IMG302-B- Nilla,S.T., M.T.-R713 } \\
\text { IIG210-E- ARNES,S.T., M.Sc.-R714 } \\
\text { IIG210-D- Winnie,S.T., M.Si.-R716 } \\
\text { IIG210-C- Dian,S.T., M.T.-R717 }\end{array}$ \\
\hline $\begin{array}{l}16: 20- \\
17: 05\end{array}$ & IIU201-A- Dr. Tiena,-R717 & & & $\begin{array}{l}\text { IIO304-- Imam,-R618 } \\
\text { IIG210-E- ARNES,S.T., M.Sc.-R714 } \\
\text { IIG210-D- Winnie,S.T., M.Si.-R716 } \\
\text { IIG210-C- Dian,S.T., M.T.-R717 }\end{array}$ \\
\hline
\end{tabular}

Diharapkan untuk penelitian selanjutnya dapat menerapkan metode hybrid GA dengan metode metaheuristik lainnya yang dapat memberikan solusi yang lebih baik dan jadwal yang ideal sesuai dengan yang diinginkan.

\section{Daftar Pustaka}

Anamisa, D. R., Djunaidy, A. (2014). Penyelesaian Penjadwalan Matakuliah Menggunakan Hibridisasi Algoritma Genetika dan Algoritma Semut. Jurnal Ilmiah Teknologi Informasi, 12(1), 15 - 20.

Balcilar, M. (2020). TimeTabling Genetic Algorithm, [Online], Diakses dari https://www.github.com/muhammetbalcilar/ TimeTabling-GeneticAlgorithm, [2020, Mei]

Basak, R., Sanyal, A., Kumar, S., \& Goswami, R. (2013). Comparative View of Genetic Algoithm and Pattern Search for Global Optimization. International Journal of Engineering and Science, 3(4), 09-12.

Carter, M \& Laporte, G. (1996). Recent developments in practical examination timetabling. Proceedings of the 1st International Conference on the Practice and Theory of Automated Timetabling, Lecture Notes in Computer Science 1153, 3-21.

Erben, R. W., \& Kepler, J. (1995). A Genetic Algorithm Solving a Weekly Course Timetabling Problem. Proc. of the First Int. Conf. on the Practice and Theory of Automated Timetabling (ICPTAT), 21-32.
Gen, M. \& Cheng, R. (1997). Genetic Algorithm and Engineering Design. New York: John Wiley \& Sons, Inc.

Jat, S. N. (2012). Genetic Algorithm for University Course Timetabling Problems. Thesis. Department of Computer Science University of Leicester.

Priambodo, M.A., Nhita, F., \& Aditsania, A. (2016). Penjadwalan Mata Kuliah Menggunakan Metode Hybrid Algoritma Genetika dan Algoritma Koloni Semut. EProceeding of Engineering, 3(2), 3711-3720.

Saini, N. (2017). Review of Selection Methods in Genetic Algorithms. International Journal of Engineering and Computer Science ISSN:2319-7242, 6(12), 23261-23263.

Sivanandam, S.N., Deepa ,S.N. (2008). Introduction to Genetic Algorithms. Berlin: Springer-Verlag.

Wati, D. A. N., \& Rochman, Y. A, (2013). Model Penjadwalan Matakuliah Secara Otomatis Berbasis Algoritma Particle Swarm Optimization (PSO). Jurnal Rekayasa Sistem Industri, 2(1), 22-31.

Wen-jing, W. (2018). Improved Adaptive Genetic Algorithm for Course Scheduling in Colleges and Universities. International Journal of Emerging Technologies in Learning, 13(6), 29-42.

Yudong, Z., Shuihua, W., Genlin, J., \& Zhengchao, D. (2013). Genetic Pattern Search and Its Application to Brain Image Classification. Hindawi Publishing Corporation Mathematical Problems in Engineering, Vol. 2013, 1-8. 
DOI: https://doi.org/10.26593/jrsi.v9i3.4093.201-212

Halaman ini sengaja dikosongkan.

This page is intentionally left blank. 